\title{
III
}

\section{VISCERAL MANIFESTATIONS OF ERYTHEMA OF THE NINTH DAY SYNDROME}

By LEON GOLDMAN, M.D., and ALFRED L. WEINER, M.D.

IN the present popularity of the study of syphilis, especially in America, relatively little seems to be said of the toxic reactions to therapy. Some of these are merely uncomfortable; some, however, are so severe as to interfere with effective treatment. According to Genner," "Erythema (dermatitis) is one of the most frequent by-effects in the modern treatment of syphilis with salvarsan and bismuth." There are various types of it, some benign and some quite serious.

One of its forms is the much discussed Erythema of the Ninth Day. This was first described by Milian ${ }^{2}$ (I920), who found a certain form of erythema occurring 8-Io, more commonly 9, days after an injection of an arsphenamine. According to Schreiner, ${ }^{3}$ older writers on syphilis therapy had apparently noted such cutaneous reactions but had not separated this group clearly from other forms of post-arsphenamine erythema. This skin reaction is observed, of course, more commonly during the treatment of a patient with syphilis but may occur in other conditions in which the arsphenamines are used. The syndrome has been reported following gold injections and also bismuth. ${ }^{4}$

The usual classical picture is seen in a patient with early syphilis, who, curiously enough, some 8-10 days after the first or second arsphenamine develops fever, malaise, weakness, joint pains and a generalised nonpruritic eruption, morbilliform or scarlatiniform in character. Frequently there may be moderate swelling of the cervical lymph glands. In fact, objectively, the patient looks like a patient with measles of a moderate severity. The patient is ill for some 4-5 days, the temperature falls gradually and the rash disappears without desquamating. The patient continues his arsphenamine course and develops no further reactions.

Although the syndrome of E.9 (Erythema of the Ninth 


\section{BRITISH JOURNAL ÖF VENEREAL DISEASES}

Day) was mentioned but not marked for distinction by earlier authors, apparently this unusual complication is described more commonly at the present time. The more intensive arsenic therapy of the modern therapeutic scheme may be a factor in this. The complication is, however, still uncommon and somewhat less frequent than the other post-arsphenamine reactions. The incidence of serious post-arsphenamine dermatitis varies as follows:

$\mathrm{I}$ in I,850 injections of arsphenamine (Meirowsky).$^{\mathbf{5 ,}} \mathbf{6}$ I in 5,370 injections of neoarsphenamine

2 I in 47,000 injections (Moore and Keidel). ${ }^{5,6}$

(Meirowsky). ${ }^{5,6}$

38 in 44,000 injections (Cathcart and Stokes). ${ }^{6}$

Io in I5,000 injections of neoarsphenamine-I938 and I937 (Cincinnati General Hospital).

Moore ${ }^{6}$ writes, " with us this drug (neoarsphenamine) is more frequently at fault than old arsphenamine." In our large clinic and hospital service, with approximately 7,500 injections of neoarsphenamine yearly, only 5 cases of E.9 have been observed in the past two years. The frequency of E.9, as of the serious post-arsphenamine dermatitides, is not different following a separate arsphenamine course than following a mixed arsphenamine and bismuth course.

From the brief clinical outline of such a case it is seen readily that such a diagnosis is not only of academic interest but also of practical value, for the patient apparently can continue with injections of the arsphenamines. This is not true with most of the postarsphenamine reactions of the morbilliform or, of course, maculo-papular-vesicular types. Milian believes that Erythema of the Ninth Day is a peculiar group of reactions quite distinct from the more common allergic skin reactions to the arsphenamines. His reasons are, first, that arsphenamines may be continued safely, secondly, that the erythema is found not infrequently endemically, and, thirdly, that the clinical course is similar to that of a preceding systemic infection in the patient, like scarlatina, rubeola, rubella, etc. Schreiner ${ }^{3}$ studied a series of cases occurring with almost epidemic form. Milian's explanation is that E.9 is a reaction of biotropism, ${ }^{7}$ the aggravation of a previous latent infection by the arsphenamine. 


\section{VISCERAL MANIFESTATIONS OF ERYTHEMA}

Many do not agree with this hypothesis, claiming that there are no definite records of any cross infections from the varied forms of post-arsphenamine skin reactions, that crops of erythema are correlated rather definitely with toxic batches of arsenic, that sometimes the mildness of the clinical picture can suggest no type of infectious exanthem, and that the eruption, may occasionally be ushered in and continue with pruritus, which is uncommon in measles and scarlet fever. Finally, they state that further treatment with arsphenamines is by no means always safe. From a recent and detailed study of the by-effects of arsphenamine therapy, Genner ${ }^{1}$ concludes, "In the present material, moreover, an incubation period of about 9 days is by no means so frequent that it justifies the establishment of a special type which is not warrantable morphologically." Such incubation periods, he claims, may vary because of the injected amounts of the arsphenamines or because of the difference in individual hypersensitivity. Apparently all are agreed that Erythema of the Ninth Day is in no way a cutaneous Herxheimer reaction. The subject of E.9 has been reviewed in detail by Keim ${ }^{8}$ in 1935 and by Gordon ${ }^{9}$ in I936.

Until extensive critical surveys are made, one must admit the existence of an unusual and relatively benign group of post-arsphenamine skin reactions in certain patients. In these patients additional arsphenamine usually causes no reactions, or at least is much less apt to cause reactions than when preceded by the other more common and more serious forms of post-arsphenamine erythemas. The cause is still unknown-either it is a reaction of biotropic influence, or of pharmacologic-toxic change, or of an allergical response ; at the present time most believe in the allergic mechanism. The allergy is supposed to be " cutaneo-vascular" as compared to the supposed epidermal allergy of the ordinary and major post-arsphenamine dermatitis.

Our interest, however, is in the systemic aspects of two of our cases of E.9. The other three cases were typical forms of E.9 with only slight constitutional reactions. Only one of these patients, a young coloured woman, required hospitalisation. Moore, ${ }^{6}$ who supports Milian, claims that "evidence of damage to the liver, kidneys, and bone marrow are lacking." In addition to the 


\section{BRITISH JOURNAL OF VENEREAL DISEASES}

exanthem, fever and general complaints the only common findings have been moderate enlargement of the cervical glands. No marked visceral involvement was described in the cases in Keim's ${ }^{8}$ series, save for a note of " mild jaundice with pruritus" in Case 7. This jaundice occurred some nine days after the onset of the erythema. Recently, also, Robinson ${ }^{\mathbf{1 0}}$ has reported a case with an Erythema of the Ninth Day in whom hepatitis with jaundice developed on resumption of neoarsphenamine therapy after the rash disappeared. Robinson cites also the cases of Gougerot and Patte and of Arzac and Bargues. Recently Milian ${ }^{11}$ has described a form of meningoencephalitis, apparently benign, associated with E.9.

Case I.-C. D., 27 years old. Hospital orderly. This patient was seen first at the General Hospital on July 28th, 1937, at which time a fading generalised macular rash was present. There was a history of a penile sore three months previously, and of an ulcerative lesion, at the corner of the right side of the mouth, of some five weeks' duration. The blood Kahn test was 3 plus. The patient had received no anti-syphilitic treatment. The general physical examination at this time showed nothing remarkable except for the findings of an old mitral insufficiency. Anti-syphilitic therapy was begun on July 28th, I937, with I c.c. of a bismuth suspension. On July 3oth, I937, the patient was given $0.9 \mathrm{gm}$. neoarsphenamine without immediate untoward effect. The patient returned on August 2nd, I937, and received another bismuth injection. On this visit he made no complaint and apparently was in good health. On August 6th, 1937, he received $0.9 \mathrm{gm}$. neoarsphenamine and shortly thereafter became nauseated and vomited several times. On the following day he felt feverish and complained of pains in the abdomen and lumbar region. On August 8th, nine days after the first injection, the fever and abdominal pain persisted, and a few small papules appeared on his shoulders. Next day the rash had become generalised and the patient was acutely ill. There was no history of exposure to measles or scarlet fever or of an upper respiratory infection.

On admission to the hospital the patient appeared toxic and restless; his temperature was I02. $8^{\circ}$, pulse Ioo, respirations 20. A generalised, red, macular and fine papular rash, scarlatiniform in character, was present; 
there was no pruritus. There was generalised lymphadenopathy. A healing split papule was present at the corner of the mouth. The throat was markedly injected, tongue not remarkable. There was evidence of an old rheumatic heart disease, but the remainder of the physical examination, except for the abdomen, was essentially negative. The liver was palpable two finger-breadths below the costal margin, its edge smooth and non-tender. The admission white count was 3,700, differentialneutrophils 48 , eosinophils 2 , lymphocytes 36 , monocytes 2, stab forms 12. Repeat white count on evening of admission 3,000. The urine was negative, no bile was present. The stool was of normal colour and bile pigment was present. The Kahn test was 3 plus, blood urea nitrogen 17 , carbon dioxide 57 , icteric index 5 . The galactose tolerance test was normal. With bed rest and oral and parenteral fluids the patient's temperature fell to normal and the rash had faded entirely within thirtysix hours. At this point the patient was given $0.3 \mathrm{gm}$. neoarsphenamine and except for a slight rise in temperature following this, there was no reaction. The white count was now 5,800, and next day had risen to 9,600. Five days following this last neoarsphenamine the patient was still afebrile and feeling well, and the liver was no longer palpable; the spleen was still enlarged, $0.6 \mathrm{gm}$. neoarsphenamine was injected and there was no untoward reaction. The patient was discharged and subsequently given regular courses of anti-syphilitic treatment in the clinic. At the present time he has had two full courses (Io $\times 0.9 \mathrm{gm}$.) neoarsphenamine and two courses of bismuth. No dermatitis or other untoward symptoms have developed. The splenomegaly has disappeared entirely.

Case 2.-V. M., white, female, I 8 years old. According to records this patient was first seen in out-patient dispensary in September, I934. At this time she presented a small superficial but indolent ulcer over the left internal malleolus. No definite etiology could be established. Her blood Wassermann was negative. The ulcer responded slowly to local therapy but apparently healed and the patient was not seen again until October, 1937, when she returned to the dispensary with a small chronic ulcer over the external malleolus on the left. The only relevant detail in her history was that 


\section{BRITISH JOURNAL OF VENEREAL DISEASES}

she had married recently. Examination of her husband revealed a gonorrhœal urethritis but no evidence of syphilis. Although prenatal syphilis could not be established, a check-up of the patient's family revealed a latent syphilis in a sister. On this admission the blood Kahn of the patient was 3 plus. Morphologically her leg ulcer appeared to be ecthymatous and not syphilitic. Before anti-syphilitic therapy was started the ulcer had healed entirely with mild local therapy. The patient was given the following therapy in the venereal clinic :

October $5^{\text {th. }} 0.6 \mathrm{gm}$. neoarsphenamine-no reaction.

October I8th. 2 c.c. bismuth subsalicylate.

October 2Ist. $0.6 \mathrm{gm}$. neoarsphenamine-no reaction.

On October $25^{\text {th }}$, ten days after the first injection of neoarsphenamine, the patient returned complaining of fever, chills, vertigo, blurred vision, nausea and emesis, abdominal pain, dysuria and leukorrhœa. Most of these symptoms had been present the day previously. There was no history of exposure to any contagious diseases. There was likewise no history of any upper respiratory infection.

On admission the patient appeared uncomfortable and acutely ill, with a temperature of $103^{\circ}$. Under the artificial light the skin was clear. The pharynx was moderately injected. The chest was clear. The only finding of note in the abdomen was an enlarged, tender spleen palpable two finger-breadths below the costal margin. Pelvic examination revealed a diffuse leukorrhœa, cervix pulled to the right and markedly tender to manipulation, and tenderness in both fornices. A mass was present in the left fornix. The white count varied from 6,000 to 8,000 with no abnormal changes in the differential count. The urine was repeatedly negative save for traces of acetone. No bile was present. The stools contained bile.

The temperature fell the next morning but rose again in the evening. At this time a definite generalised scarlatiniform erythema was present and was most marked on the trunk. There was no pruritus. The white count remained between 6,000 and 8,000 . There was no change in the pharyngeal findings. The tongue showed no 


\section{VISCERAL MANIFESTATIONS OF ERYTHEMA}

changes at all. The edge of the liver now became palpable and tender. There was no apparent change in the size of the spleen. The erythema faded within fortyeight hours, and the temperature fell gradually. Our diagnosis then was an E.9 syndrome associated with hepatomegaly and splenomegaly. Additional laboratory data at this time included a red count of 3,900,000 with II gm. of hæmoglobin; sedimentation rate, 32 ; a cervical smear which showed Gram-negative intra-cellular diplococci. The patch test was positive $(\mathrm{I}-2)$ for neoarsphenamine. The Prausnitz-Küstner transfer test was negative for neoarsphenamine.

At the time of the complete disappearance of the erythema and the lack of sustained fever, approximately six days after the onset of the E.9, the patient was given $0.3 \mathrm{gm}$. neoarsphenamine intravenously. Some slight paravenous infiltration was reported at the time of the injection. Two hours after the injection the patient developed a generalised urticaria, the temperature rose slightly, and the patient again developed an erythema similar to that of her previous episode. There was no change in the liver and spleen. The relative leucopenia persisted. The rash faded completely in forty-eight hours. It was noted that the patient was icteric. The urine contained bile pigment. Hydrobilirubin was present in the stool. The icteric index varied, over a period, from 56 to 16 . The biliary drainage contained no pus cells. The galactose tolerance test showed $3 / \mathrm{I} 5 \mathrm{gm}$. of sugar recovered. The Van den Bergh gave a strong direct action. The blood urea nitrogen and carbon dioxide were within normal limits. The patient volunteered the fact that she had had attacks of urticaria for some years. She definitely attributed these to the ingestion of tomatoes. (This was later established when the patient developed an urticaria after the ingestion of tomatoes.)

Under general therapy, including intravenous glucose, the icterus subsided completely, both from clinical and laboratory studies, within 2 weeks. The liver and spleen were no longer palpable. The patient was discharged to the venereal clinic.

Here for ten weeks the patient received injections of intramuscular bismuth. After this period she was readmitted for study. At this time her physical examina- 


\section{BRITISH JOURNAL OF VENEREAL DISEASES}

tion was entirely negative. The blood Kahn was 3 plus, the red count 4,600,000 with I4 gm. of hæmoglobin. The white count was now 9,400 with completely normal differential. The urine was entirely negative. The stool was coloured and contained no mucus, pus, or blood. The icteric index was 6, the Van den Bergh showed no direct action and the bromsulfalein revealed less than 5 per cent. retention. The blood urea nitrogen and carbon dioxide were normal.

After these studies were completed, about $2 \frac{1}{2}$ months after subsidence of her icterus, the patient was started again on neoarsphenamine. The doses were first 0.15 , then 0.3 and $0.45 \mathrm{gm}$. respectively. The patient has been maintained on weekly injections of $0.4 \mathrm{gm}$. There has been no subjective or objective reaction to approximately 9 injections of neoarsphenamine.

These two cases, then, presented interesting and significant systemic involvement with a clinical picture of E.9. Case I, in addition to the usual findings of E.9, showed a marked leucopenia, hepatomegaly, and splenomegaly, not aggravated by immediate and subsequent neoarsphenamide therapy. $\mathrm{He}$ has been attending the clinic regularly for almost a year and has had no reactions at any other time.

Case 2 is a bit more difficult of analysis. The initial part of her post-arsphenamine reaction was certainly typical of E.9. The subsequent course following $0.3 \mathrm{gm}$. neoarsphenamine was indeed surprising to us who have had only a brief experience with this syndrome. The history showed the urticaria to be of no significance. Subsequent intensive neoarsphenamine therapy after an interval of two and one half months produced no recurrence of skin or visceral reactions. Unlike Schreiner's ${ }^{3}$ cases, no Prausnitz-Küstner transfer reactions could be obtained. An intradermal neoarsphenamine test was not done in Case 2. In E.9, the reported positive intradermal tests to neoarsphenamine and the reported positive passive transfer tests would favour the theory of allergic response. The eczematoid patch test reaction, as exhibited in Case 2, remains a subject of much controversy for explanation of the varied post-arsphenamine cutaneous reactions. The relatively large dose of neoarsphenamine given to these two patients may be questioned as possible active rôles in producing this syndrome. Dosage, how- 
ever, is not supposed to be related proportionately either to the frequency or to the severity of E.9. Neither of these cases showed an eosinophilia at any time. The paravenous infiltration in Case 2 apparently had no rôle, since the exanthem occurred only two hours after injection. It is interesting that both these cases were associated with a mixed arsphenamine and bismuth course.

In I925 Milian 2 stated that " Erythema of the Ninth Day can be accompanied by jaundice at times." $\mathrm{He}$ described a case of early syphilis, in a man 27 years old, with the following relevant details :-

$\begin{array}{ll}\text { June 28th } & \text {. } 0.4 \text { salvarsan } \\ \text { July Ist } & \text {. } 0.4 \text { salvarsan } \\ \text { July 5th } & \text { Fever, eruption (E.9) } \\ \text { July 7th } & \text { : Erythema subsiding } \\ \text { July IIth } & \text { Erythema disappeared entirely } \\ \text { July I2th } & \text { - }\end{array}$

Milian further stated, "When it is a question of infectious icterus, catarrhal or complicated by an Erythema of the Ninth Day, as I have been given to observe some rare cases, specific medication ought to be discontinued, at times, for sufficiently long period. One must not insist, for a moment, on specific treatment which might aggravate the jaundice and even cause a fatal reaction (acute yellow atrophy?). When one continues specific medication, at the same dosage in these circumstances, one ascertains, each time, at each injection the aggravation of the icterus and of the functional disturbances." According to Milian, then, Case 2 was an example of what he would call a biotropic hepatitis and not a post-arsphenamine hepatitis.

Genner, ${ }^{1}$ on the other hand, states, " the occurrence of a hepatitis in association with dermatitis is to be interpreted as a toxicosis concurrent with the skin lesion, and the coincident cutaneous and parenchymatous lesions constitute merely a manifestation of a more severe intoxication, i.e., they represent merely a difference of degree." However, again, the important practical point is that even with a diffuse hepatitis, further therapy can be given without immediate clinical or laboratory evidences of reactions. This certainly would not occur with a liver hypersensitive to arsenic. Arsenic excretion 


\section{BRITISH JOURNAL OF VENEREAL DISEASES}

studies have been done for some time and in some detail in Case 2 but no definite conclusions can be drawn at the present time. Case 2 is still being followed with detailed liver functions studies and will continue to be followed. Apparently in the other cases reported in the literature $\mathbf{1 0}$ arsphenamine therapy was not continued immediately after the hepatitis subsided.

It is obvious that from a study, including follow-up observations, of only two cases of complicated Erythema of the Ninth Day one cannot make a dogmatic statement as to whether or not the same therapy can be continued immediately. One can say, however, that there is no apparent danger when the acute symptoms have subsided. Of course, in E.9 without visceral involvement, the specific therapy can be continued soon and safely.

\section{CONCLUSIONS}

Two cases are presented, corresponding to what to-day is called the syndrome of Erythema of the Ninth Day (E.9), following intravenous neoarsphenamine. In one, the syphilis was an early infection; in the other, apparently a latent one. These cases show that severe visceral involvement can occur with E.9, Case I with splenomegaly, hepatomegaly and marked leucopenia as most evident findings, Case 2 with relative leucopenia, splenomegaly, and diffuse hepatitis with icterus as the most obvious involvements. Immediate continuation of neoarsphenamine during the acute episode caused no reaction in Case I ; in Case 2 the therapy caused relapse of the skin manifestations and icterus; specific treatment, however, was resumed after a brief interval and produced no reactions. For the rare case of Erythema of the Ninth Day with marked visceral involvement the intravenous arsenicals may be continued with caution immediately after the acute symptoms have subsided.

\section{REFERENCES}

(I) Genner, V.: "By Effects in Salvarsan Therapy and Their Prevention." Levin and Munksgaard ; Ejnar Munksgaard. Copenhagen, 1936.

(2) Milian, G. : Lictère parathèrapeutique, Rev. franç. de Dermat. et de Venereol, $\mathrm{r} 925,3, \mathrm{I} 8 \mathrm{o}$.

(3) Schreiner, K. : Uber Milians " Erythem des 9 Tages," Arch. $f$. Derm. u. Syph., I932, 167, 94. 


\section{VISCERAL MANIFESTATIONS OF ERYTHEMA}

(4) Goldman, Leon and George E. Clarke: " Erythema of the Ninth Day Syndrome Associated with Bismuth Therapy (in press).

(5) Stokes, John H.: "Modern Clinical Syphilology. W. B. Saunders Co., Phila., I928.

(6) Moore, Joseph EArle : "The Modern Treatment of Syphilis," Chas. C. Thomas, Baltimore, r933.

(7) Milian, G. : Biotropism, Deliber. Congr. Dermat. Internat. 9, 2-7, I935; ab. Year Book of Dermatology and Syphilology, I937, p.I25. The Year Book Publishers, Inc., Chicago, I938.

(8) Keim, Harther, L. : "Erythema of the Ninth Day," Arch. Derm. and Syph., I935, 37, 29 I.

(9) Gordon, H. : "Erythema of the Ninth Day" (Milian), Brit. J. Dermat., I936, 48, 28 I.

(io) Robinson, Saul S. : "Erythema of the Ninth Day," Arch. Derm. and Syph., I938, 37, I03I.

(II) Milian, G. : " L'erythème du neuvieme jour avec encephalite," Bull. et Mem. de la Soç. Med. des Hop. de Paris, I937, 53, I372 ; ab. Ann. de Derm. et de Syph., I938, 9, 222. 